\title{
SOBRE LOS ALÓFONOS DENTALES DE \%/
}

Es sabido que el sistema fonológico del castellano conoce, en el orden de los fonemas alveolares, el fricativo linguoalveolar sordo, $/ \mathrm{s} /$. Las realizaciones fonéticas que se suelen señalar a este fonema son las siguientes: fricativa linguoalveolar sorda, $[s]$; la fricativa linguodental sorda, [s]; la fricativa linguoalveolar sonora, $[z]$; y la fricativa linguodental sonora, $[z]^{1}$.

El origen de estos cuatro sonidos hay que buscarlo en el Manual de pronunciación española, de Navarro Tomás, donde se describen del siguiente modo: la $[z]$ uaparece únicamente, en nuestra lengua, en posición final de sílaba, precediendo inmediataniente a otra consonante sonoran"; la [s]: "La $s$ final de sílaba, en contacto con una $t$ siguiente... toma el punto de articulación de la $t$, formándose con la punta de la lengua contra la cara interior de los incisivos superiores, y no contra los alvéolos de estos mismos dientes, como ocurre en los demás casos» 3; la [z]: "De un modo semejante, la $s$ sonora; $z$, en -contacto con una $d$ o $\vec{d}$ siguientes, deja su articulación alveolar, formándose contra los dientes, como estas mismas consonantesı" 4

De este modo, según la descripción del Manual de pronunciación, los cuatro alófonos de $\mid s /$ aparecerían en distribución complementaria: $[s]$ ante vocales, consonantes sordas labiales, alveolares, palatales 0 velares; $[z]$ ante consonantes sonoras labiales, alveolares, palatales $o$ velares; $[s]$ ante consonantes sordas dentales ${ }^{5}$, una, $[t] ;[z]$ ante consonantes sonoras dentales, $[d] \circ[d]$.

En este momento, vamos a fijar nuestra atención sobre los alófonos dentales $[s],[z]$.

Desde hace tiempo, desde que empezamos a trabajar en el dominio de la fonética con el sonógrafo, veníamos dudando de la existencia real de estos

1 Alarcos. Fonología española, p. 156, siguiendo la descripción del Manual de pronunciación, de NAVARRo TOMÁs.

2 P. 108.

3 P. I04.

4 Pp. 104-ro5.

- El contacto con [0] suscita otros problemas, de los que no vamos a tratar aqui. 
dos alófonos dentales ante $|t, d|$, pues observábamos enl los sonogramas que la frecuencia a la que aparecían las resonancias del ruido de la fricación eran iguales aproximadamente para $[s]$ y $[s]$. Pero, utilizando solamiente el método espectrográfico, acústico, no nos atrevíamos a confirmar nada. pues, como sabemos, un pequeño cambio de lugar articulatorio, como sería el de los alvéolos a los incisivos superiores, puede quedar compensado, por medio de una modificación de la cavidad anterior de resonancia, en el sentido de que la pequeña disminución del volumen de esta cavidad, que se produciria al pasar la articulación desde los alvéolos a los incisivos, aumentando con ello el timbre agudo de [s], podría ser equilibrada con un pequeño aumento de labialización, que devolvería a [s] su timbre característico. 'Todo esto, claro está, siempre que, al cambiar el lugar de la articulación, conservase la [s] su carácter acústico de densa y estridente, pues, si se convirtiese en difusa y mate, nos encon-

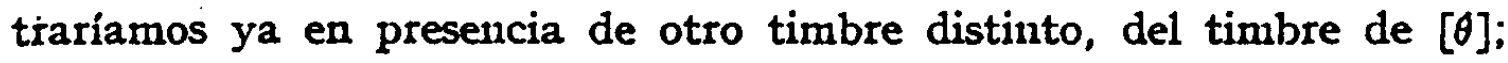
o si cambiase cualquiera de los dos rasgos, denso o estridente, por el de difuso o mate, nos encontraríanos en presencia de una de esas realizaciones andaluza, canaria o mejicanil, de carácter intermedio entre [s] $y[\theta]$, con predominio de uno $u$ otro timbre.

Cuando en I 960 se comenzaba a trabajar en el Institut de Phonétique de la Universidad de Estrasburgo en la cinerradiografía de la fonética, aceptamos la invitación del profesor Georges Straka para aplicar este procediniento a la fonética española. La cinerradiografía era precisamente el aspecto que nos faltaba en el Laboratorio de Fonética de Madrid, bastante completo ya ell aquel tiempo. Este aspecto articulatorio sería el complemento del acústico, que ya utilizábamos, y no se nos ocultaba que nos revelaria, que nos despejaría muchas de las incógnitas que teníamos planteadas ${ }^{1}$, y una de ellas era la de la existencia o no de estos alofonos dentales ${ }^{2}$.

1 De él ya dimos cuenta en otro trabajo: Datos fisiologico-acústicos para el estudio de las oclusivas y de sus correspondientes alofonos fricativos, en Homenajes, I, 1964, pp. 33-42. Ein aquel tiempo no contábamos nada wás que con tres películas realizadas sobre un informante castellano. Posteriormente, en 1965 , aprovechamos una breve estancia en Estrasburgo para realizar dos peliculas más sobre otro informante castellano. Recientemente la aparecido otro trabajo nuestro en el que danos algunos resultados cincrradiográficos solsre un campo concreto de la fonética española: Datos para el estiutio de las africadas españolas. Travaux de Linguistique et de Littérature du Centre de Philologie Romane de Strasbourg, IV, 1960, pp. 403-412.

2 Por diversas circunstancias (organización del NI Congresa Internacional de Linguiistica y Filologia Románicas, preparación de las Actas del mismo para su edición, etc.), no hemos podido terminar la redacción de este trabajo hasta este momento. En la primera edición de nuestro Curso de Fonélica y Fonologia espa- 
Al confeccionar las frases que debiamos posteriormente filmar tuvimos especial cuidado en que quedasen plasmadas todas las combinacioues posibles de nuestros sonidos. Así, la combinación $/ s+t, d /$ aparecía en las siguientes frases: "el ruido del estrecho", "un docto instructor", "una cuestión crucial", "pasas de Málaga" y "combates del Congo".

In las figuras 2 a la 6 se encuentran diversas inágenes de la realización de. $/ s+$ dental/ ${ }^{1}$. Pasemos a examinarlas.

Fn la figura I reproducimos la articulación de la $[s]$ intervocálica de "pasas». Esta articulación, por ser fonéticamente normal ${ }^{2}$ la tomamos como referencia de las demás. En ella podemos observar claramente la articulación alveolar, realizada con la parte posterior clel ápice lingual, de la [s].

En la figura 2 damos el esquema articulatorio de $/ s+t /$ en uestrechon: esta articulación se realiza también con la parte posterior del ápice lingual contra los alvéolos. Lo mismo podemos decir de los esquenras articulatorios de las figuras 3, "Instructor"; 4, "cuestión"; 5, "pasas de"; y 6, «combates del». En la posición que adopta la lengua, en cada una de estas figuras, se nota claramente una tendencia a ocupar el lugar de la articulación del sonido que le sigue, en este caso el dental 3 ; pero debemos hacer dos observaciones que nos parece son de sumo interés: en

ñolas para estudiantes angloanericanos, Madrid, 1964, deciamos en el prólogo: "Lin este manual podrán apreciarse ligeras modificaciones con relación a las ideas fonéticas precedentes; torlas ellas han sido fruto de innumerables experiencias realizadas en nucstro laboratorio, y cuyos resultados están en vias de publicación cn diversas revistas" (p. $\mathrm{XI}$ ); y al tratar de $/ s /$ omitimos ya eutonces sus alófoncs dentales (pp. 87-88). Lin la segunda edición, Madrid, 1966, pp. XI y 85-86 respectivamente.

1. Proceden de un informante madrileño, universitario, cuya habla se puede tomar como correcta en el sentido expresado por NavarRo en su Manual, pp. 8-9. El informante emitió estas frases en un conjunto de cincuenta y dos, y corresponden a los números $36,40,32,13$ y 30 .

2 Decimos que una articulación es fonéticamente normal en los siguientes casos: a) cuando se trata de la articulación fonéticamente normal de una vocal, ésta debe encontrarse durante su emisión entre dos consonantes labiales $[p, b]$, pues de este modo no influirán en la posición de la lengua; $b$ ) cuando se trata de la articulación fonéticamente normal de una consonante, ésta debe articularse entre dos vocales $[a]$, que, por ser las mís bajas, tampoco influirán en su articulación. En los dos casos son realizaciones que no están influidas por las articulaciones de su contorno. (V. Grorges Straka. Questions de Phonétique. Bulletin de la Faculté des Letlres de Strasbourg, 1955, p. 313.)

3 Hemos de advertir, antes de seguir adclante, y esto es muy importante, que todas estas frases, al igual que todos los ejemplos que constituyen el cuerpo de este trabajo, han sido emitidos a una velocidad normal de elocución, que respondería al mismo ritmo y tensión articulatoria de los empleados en el sistema ronversacional. 
primer lugar, la que se refiere a la descripción de las articulaciones de las figuras 2-6. Sabemos que la emisión de todo sonido consta normalmente de tres momentos perfectamente caracterizados: el intensivo, el tensivo y el distensivo. Estas fases aparecen también en estas articulaciones, aunque se encuentren en posición inplosiva. Durante el momento intensivo, la lengua se dirige hacia los alyéolos, formando con ellos un canal bastante ancho; durante la tensión, la lengua se acerca más a los alvéolos, formando, en ese momento, la verdadera constricción; durante la disteusión, la lengua baja hacia los incisivos superiores, buscando ya la articulación de la consonante dental. A la segunda fase, a la fase de tensión, es a la que corresponden todas nuestras representaciones articulatorias. Tin segundo lugar, no nos debe extranar que, aun siendo la articulación neta y claramente alveolar, la lengua tenga una inclinación que nos dé ya a entender cuál va a ser la articulación que sigue; esta tendencia hacia la búsqueda de la articulación siguiente es un efecto de lo que conocemos con el nombre de anticipación articulatoria. Recientemente la puesto de relieve nuestro querido colega y amigo Joseph A. Fernández ${ }^{1}$ la existencia de la anticipación vocálica en español, es decir, la tendencia que en nuestro sistema fonético existe a que la lengua ocupe la posición articulatoria de la vocal que sigue, mientras se está aún articulando la consonante, e incluso durante el momento de la tensión de la consonante que precede. Del mismo modo, aunque menos ostensiblemente, ocurre con la anticipación consonántica, sobre todo entre articulaciones que constituyen márgenes silábicos $\mathrm{y}$, por lo tanto, límites silábicos: [posición silábica implosiva + posición silábica explosiva], como ocurre en nuestro caso.

Si estamos de acuerdo en reconocer ese principio de fonética general que dice que el momento articulatorio de la tensión de un sonido es el característico, el pertinente, el que conforma lo que auditivamente reconoceremos como tal sonido, el imprescindible, el que nunca puede faltar, el que da, en fin, la configuración a ese sonido, dekemos concluir que, fisiológicamente, en la articulación $/ s+$ denial/, la realización es $[s+$ dental $]$ y $n o[s+$ dental $]$.

En las figuras 7,8 y 9 representamos los resultados acústicos de palabras que constituyen pares múuimos oponibles en st/s: estos pares mínimos son asta/asa, casta/casa, cesto/ceso, costo/coso ${ }^{2}$.

1 Joskilil A. Ferníndiz. La anticipación vocalica en español, RFE, 1963, XLVI, pp. $437-440$.

2 listos espectrogramas proceden de las realizaciones de tres informantes, uno por figura, de habla castellana, universitarios y de pronunciación también correcta; han sido emitidos tamibién a un ritmo nornal de elocución. 


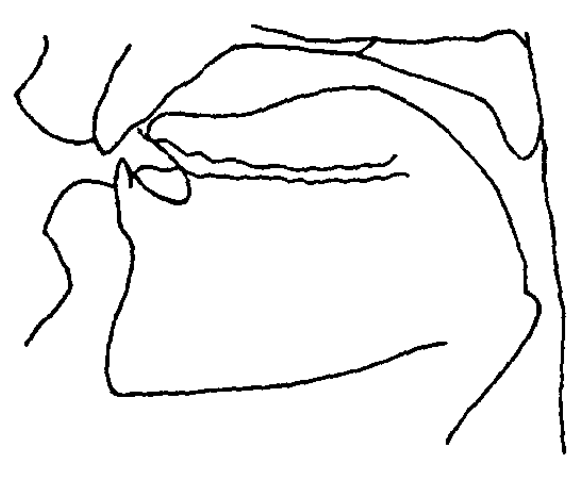

I.ig. I

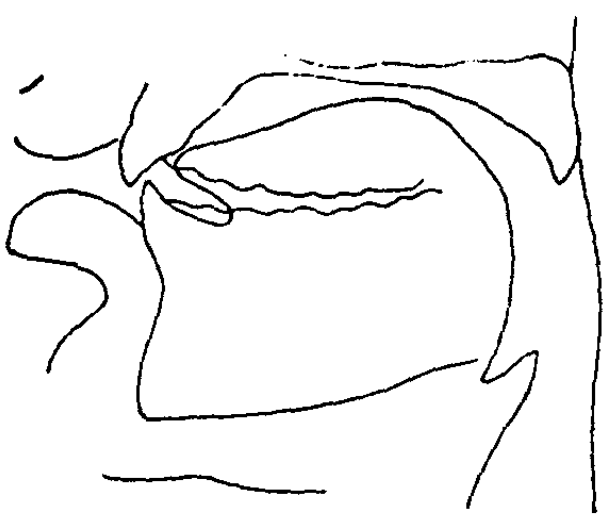

Iig. 3

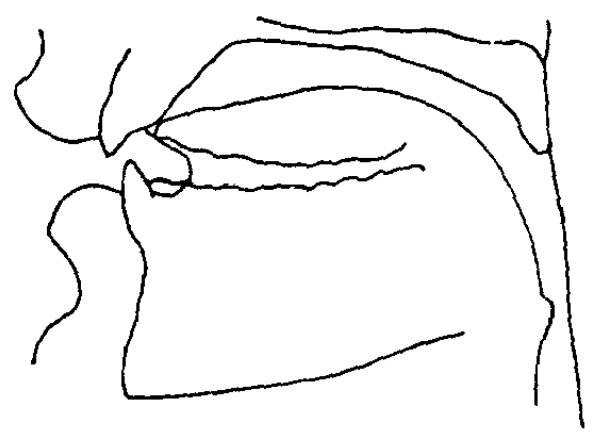

I.ig. 5

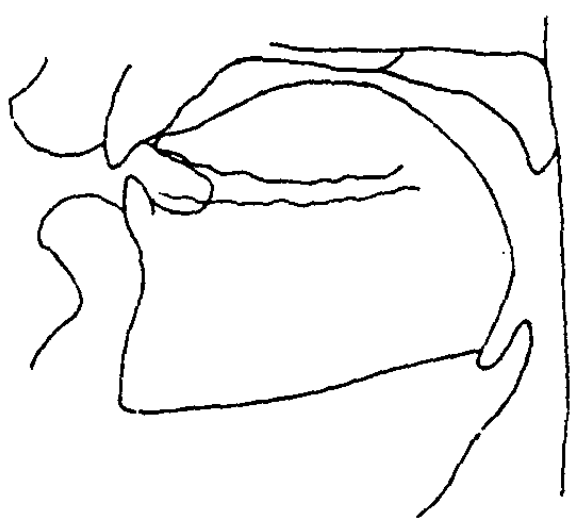

Iig. 2

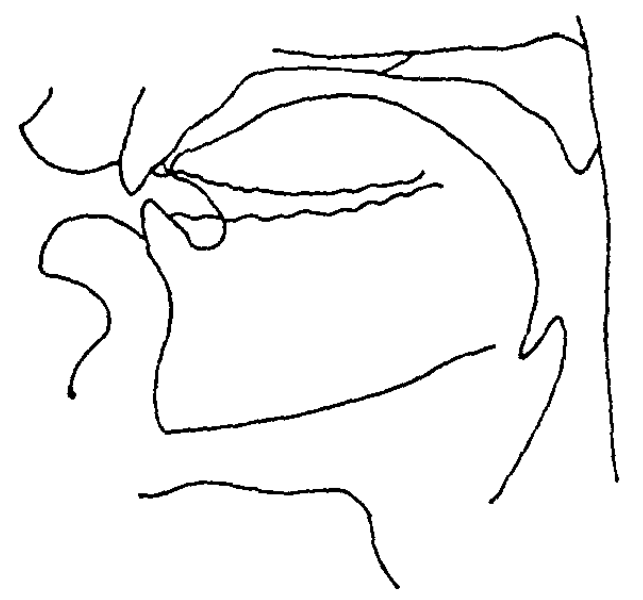

Fig. 4

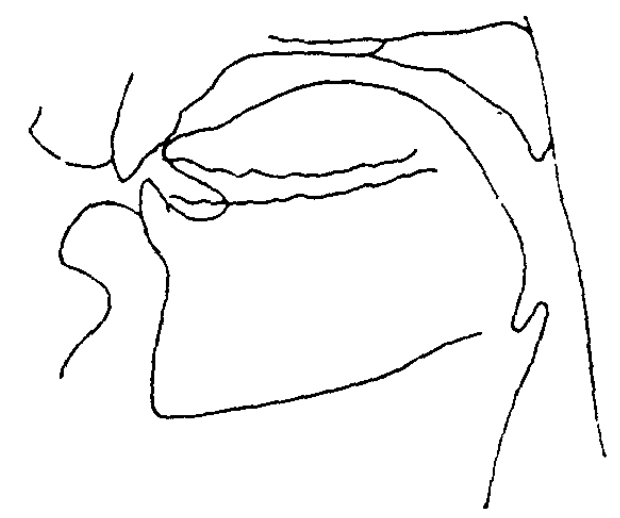

Fig. 6 

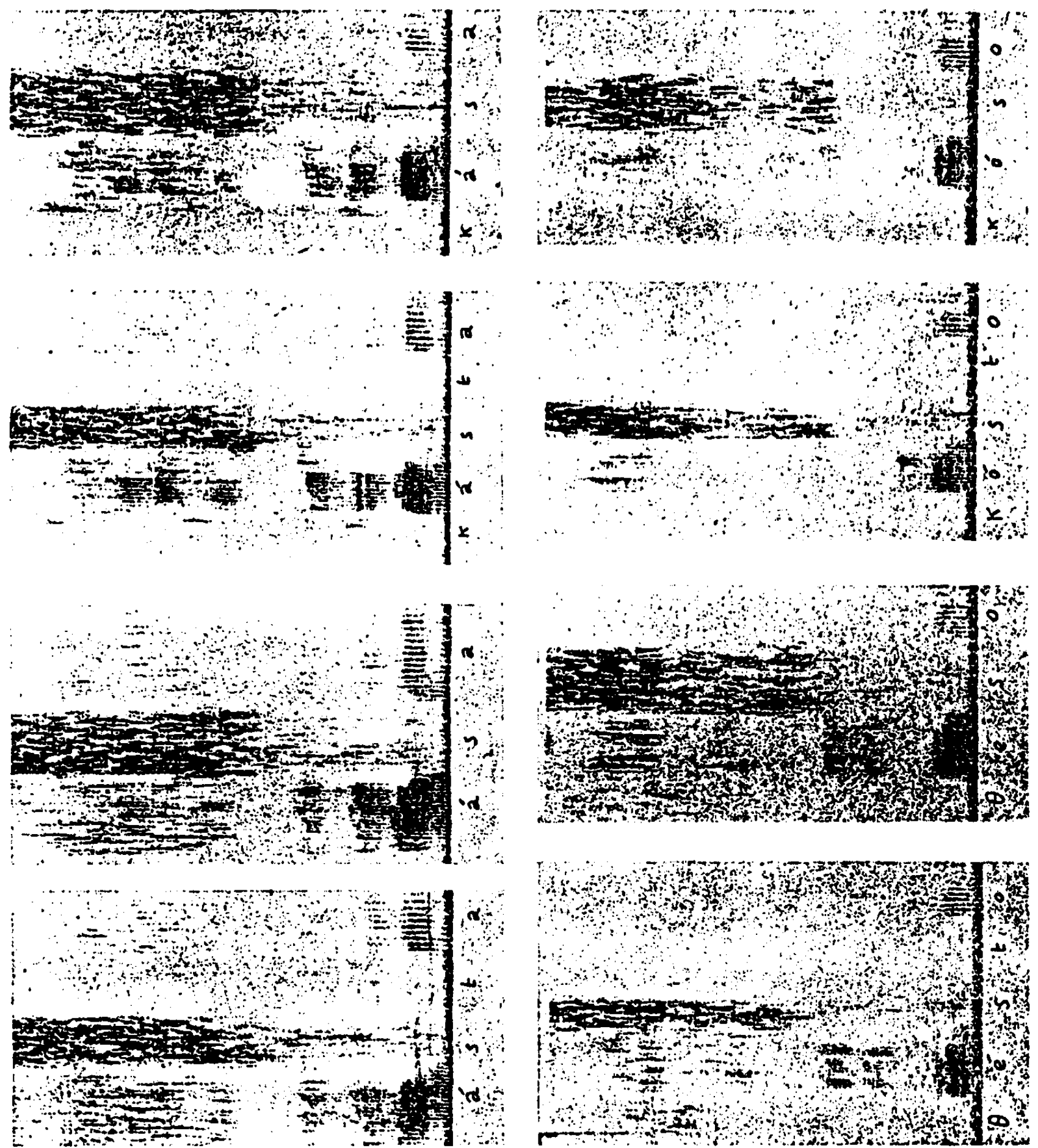

Fig. 7 

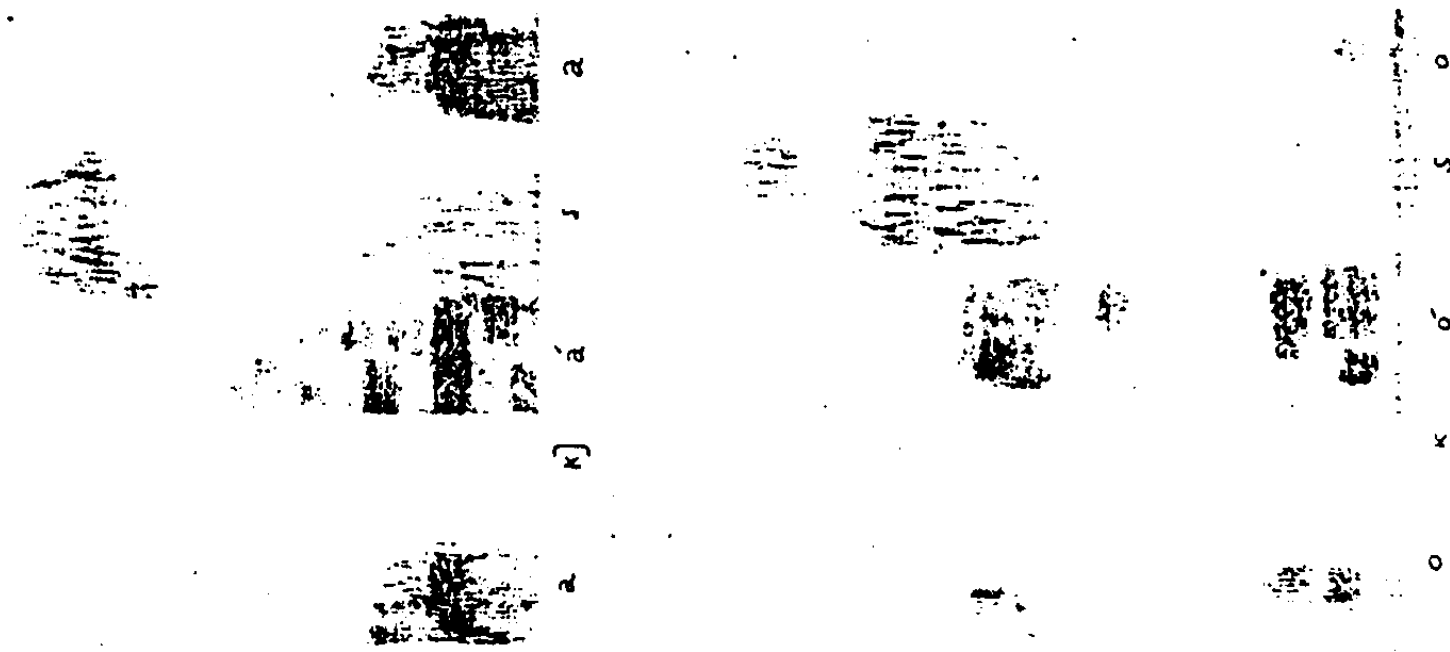

等
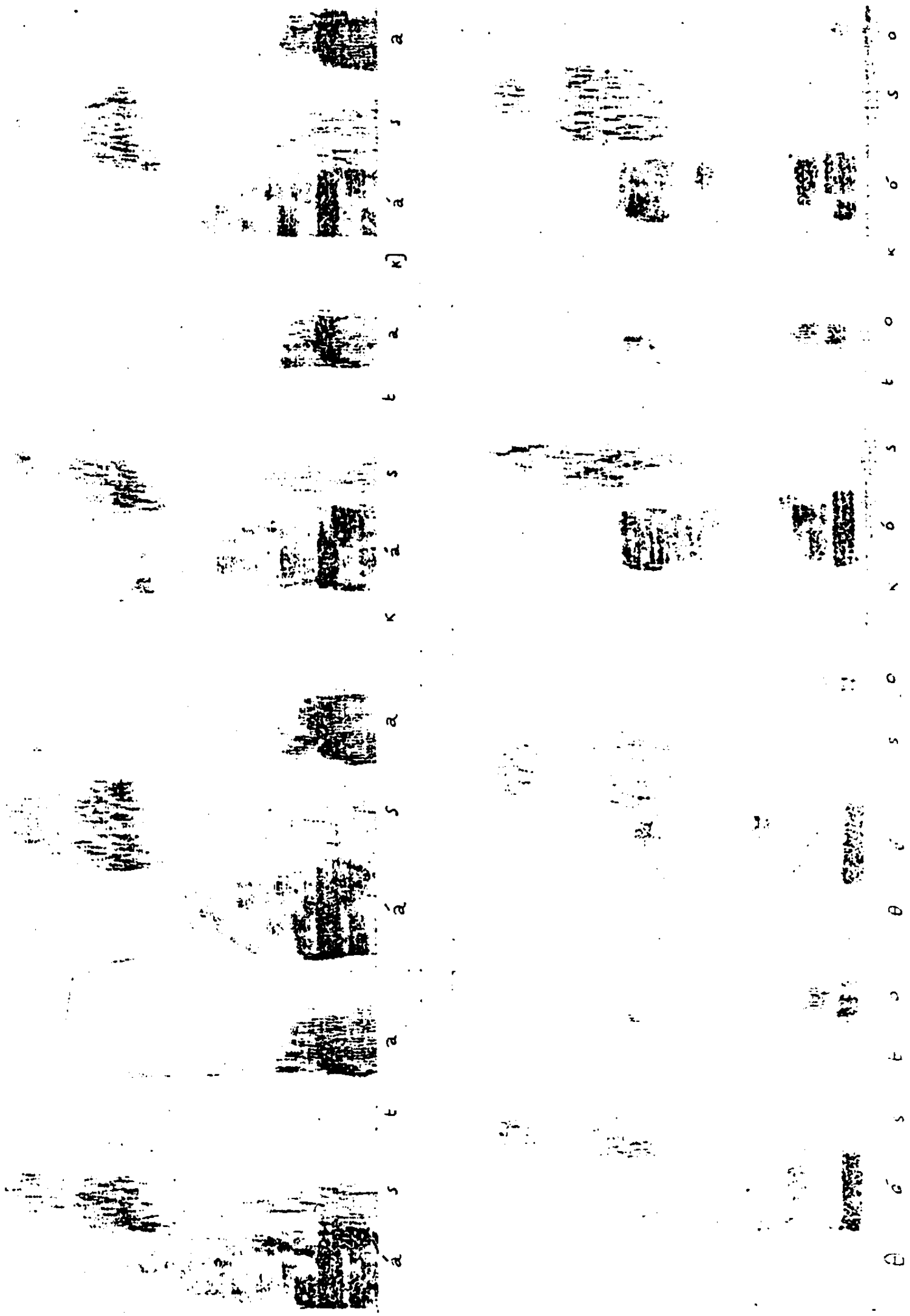

I.ig. 8 

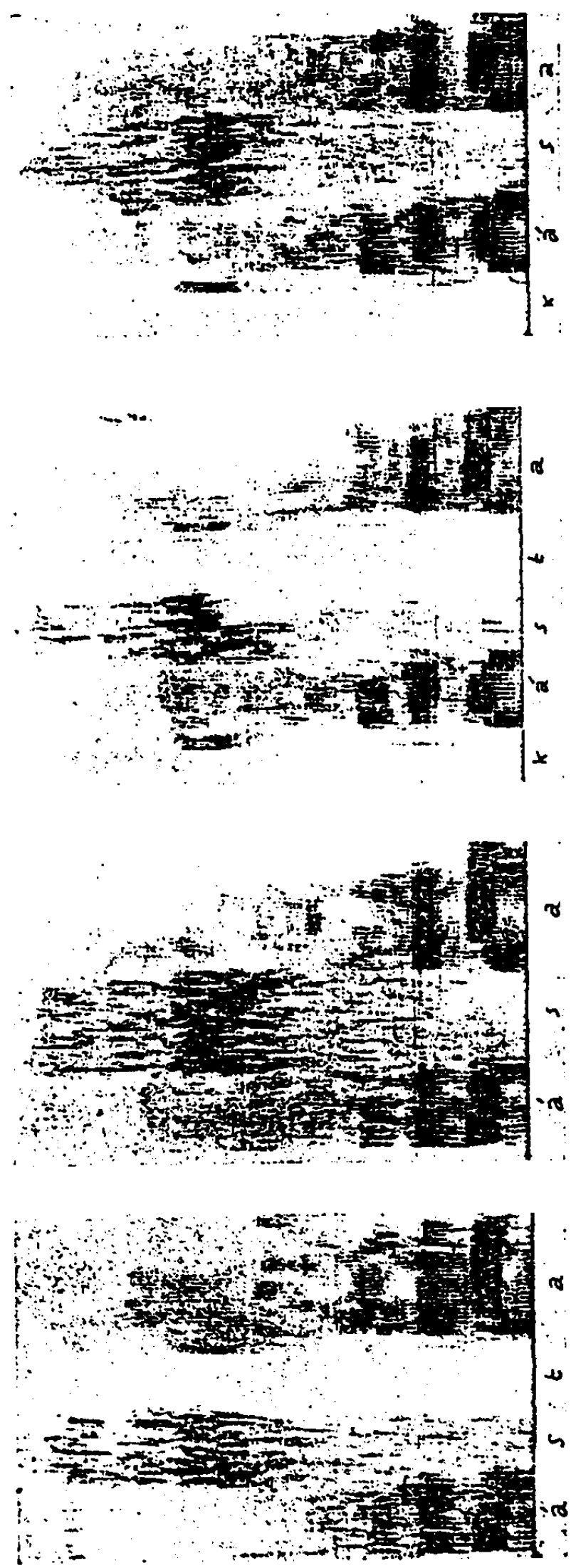
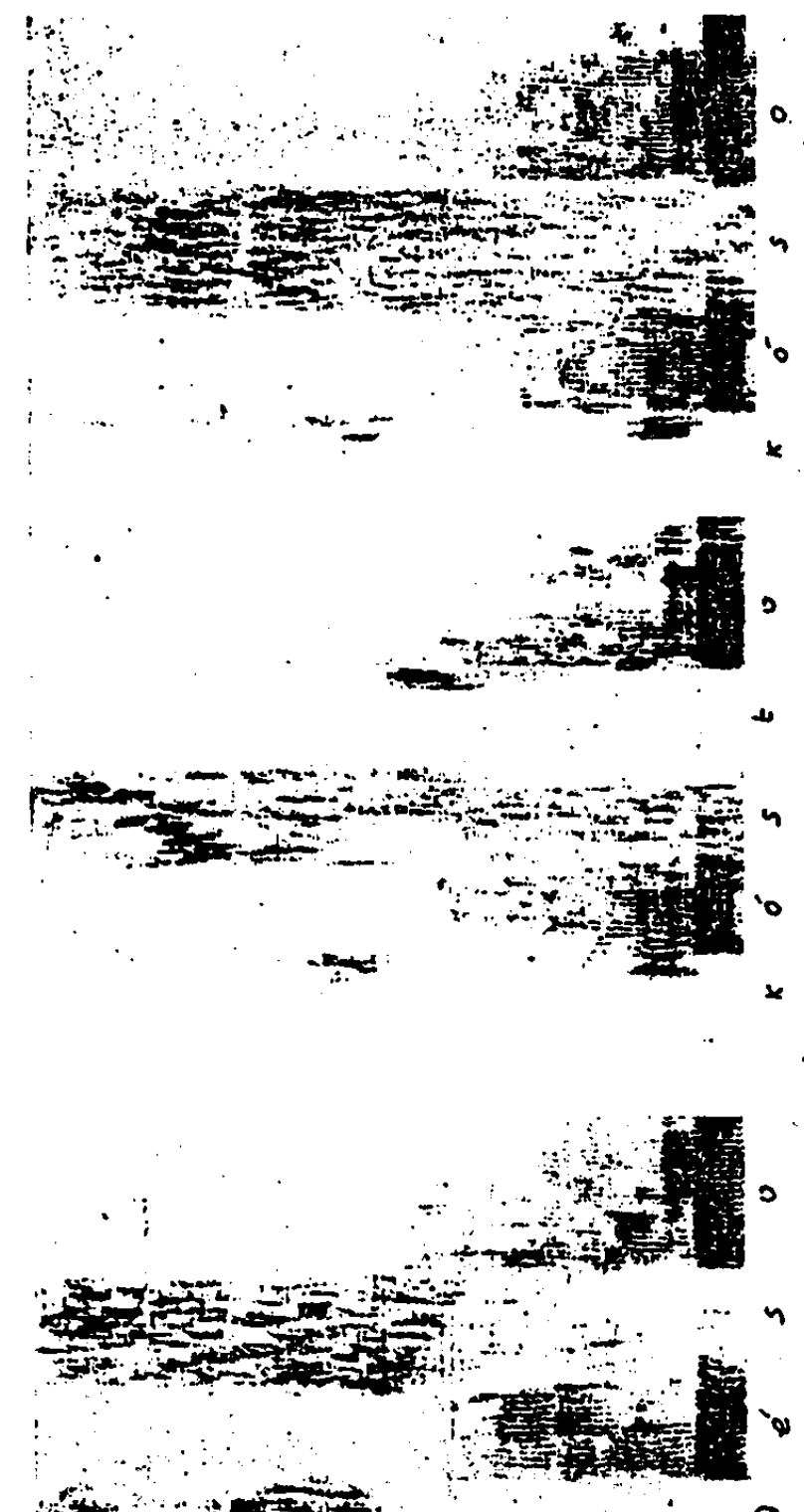

(a)

$14=0$

$\infty$
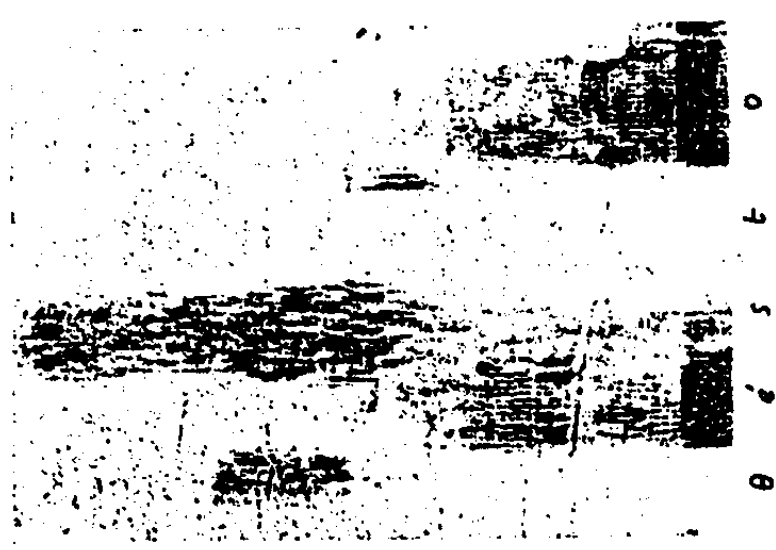

Fig. 9 

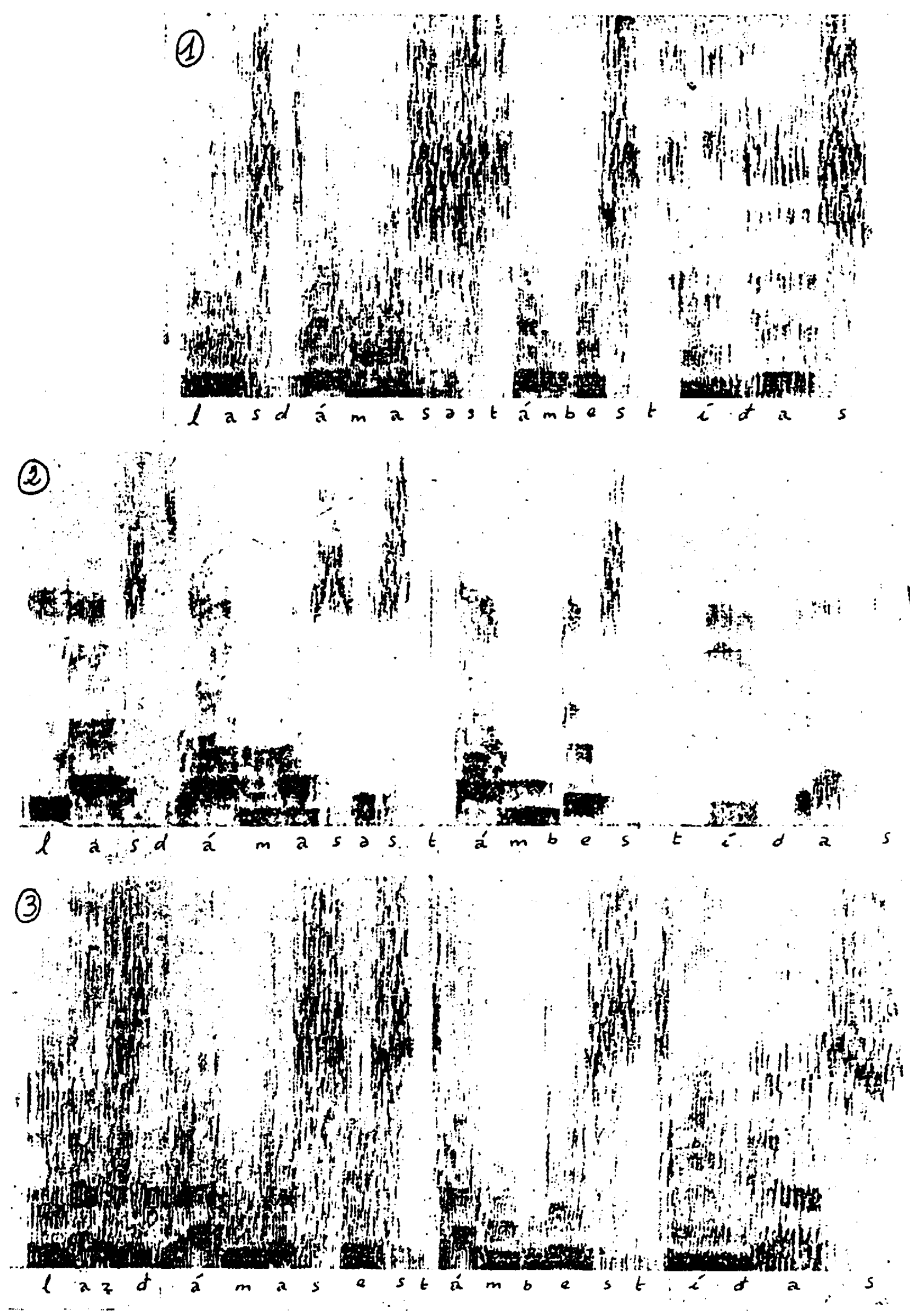

Iigs. 10

(c) Consejo Superior de Investigaciones Cientificas Licencia Creative Commons 3.0 España (by-nc) 


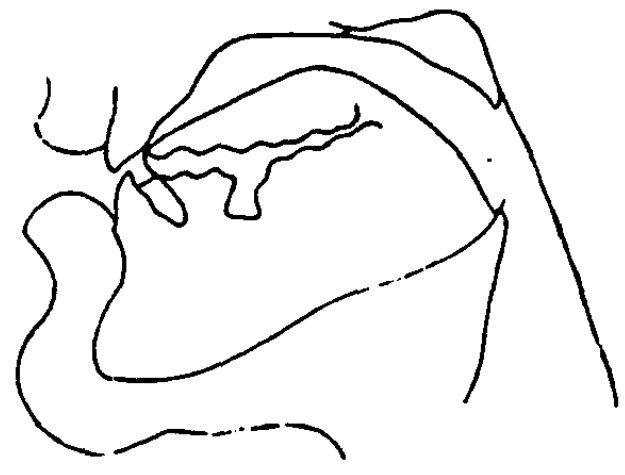

lijg. I 1

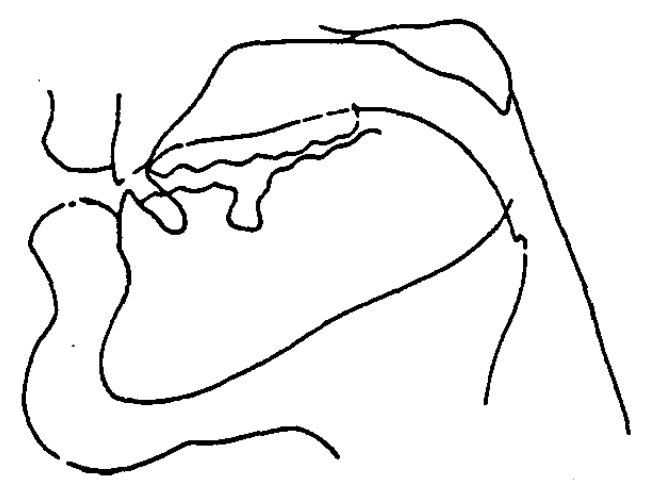

Iig. 13

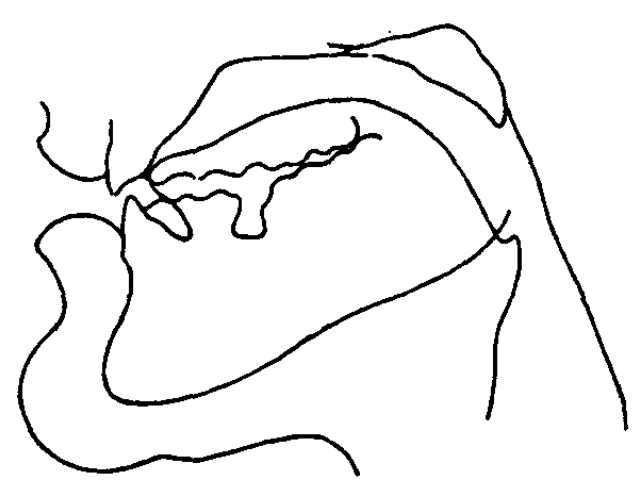

17ig. 12

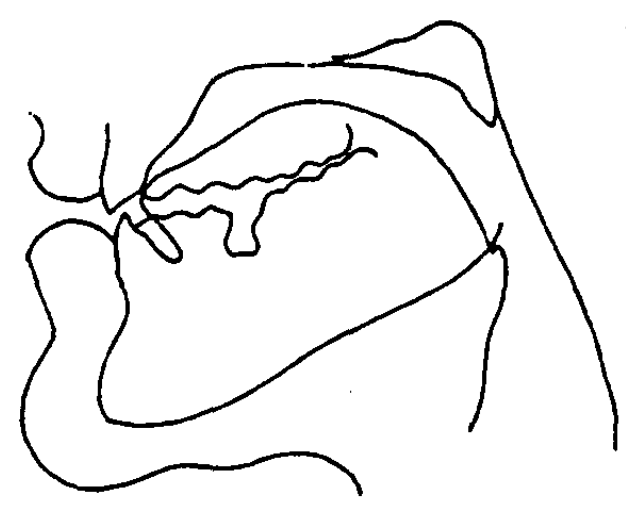

lïig. $I_{4}$

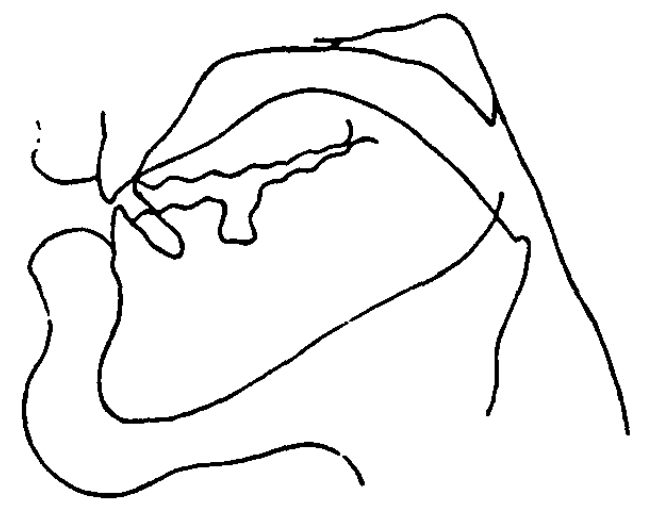

Fig. 15 


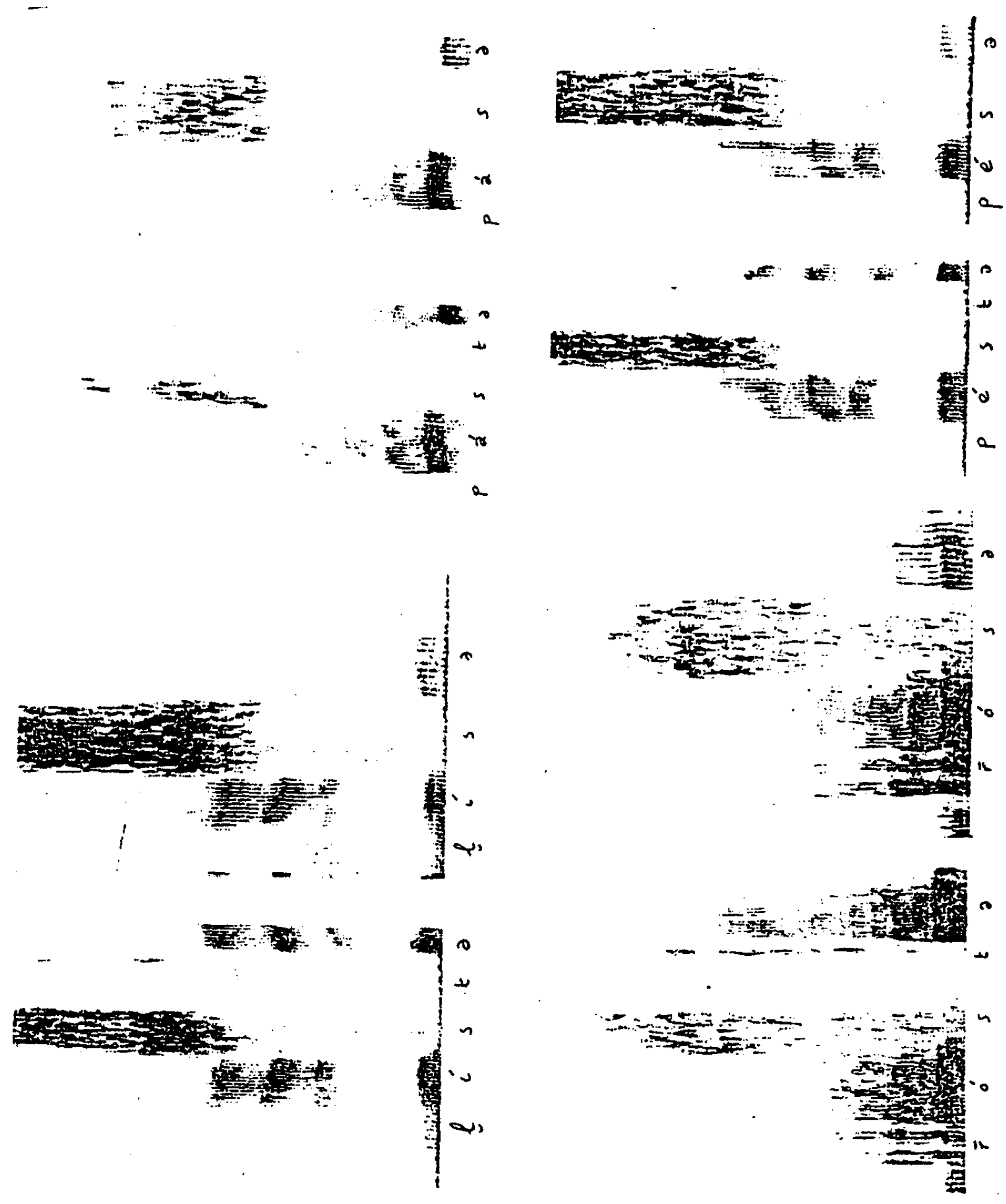

ligg. 16 
En estas figuras podemos observar:

I. - La aparición de la densidad de los componentes inarmónicos en 1a fricación de la [s] se realiza a las siguientes frecuencias, en $\mathrm{Hz}$ :

\begin{tabular}{|l|c|c|c|c||c|c||c|c|}
\hline & asta & asa & casta & casa & cesto & ceso & costo & coso \\
\hline Figura 7 & 3159 & 3150 & 3240 & 3240 & 2838 & 2673 & 2430 & 2349 \\
\hline Figura 8 & 4171,5 & 4293 & 4050 & 4212 & 3888 & 3807 & 3564 & 3483 \\
\hline Figura 9 & 4050 & 3888 & 3726 & 3807 & 3483 & 3240 & 3199,5 & 3361,5 \\
\hline
\end{tabular}

2.0 La duración de la [s] en [-st-] y en [-s-], en c. s., es la siguiente:

\begin{tabular}{|c|c|c||c|c||c|c||c|c|}
\hline & asta & asa & casta & casa & cesto & ceso & costo & coso \\
\hline Figura 7 & 8 & 12 & 7,6 & 11,2 & 6,4 & 12,8 & 0,4 & 11,2 \\
\hline Figura 8 & 12 & 17,6 & 9,6 & 16,8 & 8,8 & 16,8 & 10,4 & 16 \\
\hline Figura 9 & 0,6 & 13,6 & 11,2 & 14,4 & 0,6 & 13,6 & 10,4 & 14,4 \\
\hline
\end{tabular}

A la vista de estos cuadros podemos deducir:

I. ${ }^{-}$La diferencia de valores en las frecuencias de la [-s-] para cada informante: desde $3 \mathrm{r} 59 \mathrm{~Hz}$ en "asa" ", hasta $2349 \mathrm{~Hz}$ en "coso", para el informante de la figura 7 ; desde $4293 \mathrm{~Hz}$ enl "asa" hasta $3483 \mathrm{~Hz}$ en "coso", para el informante de la figura 8; desde $3888 \mathrm{~Hz}$ en "asa» hasta $336 \mathrm{I}, 5$ en "coso", para el informante de la figura 9; es decir, unas variaciones de frecuencias bastante considerables. Estas variaciones son normales, puesto que de la $[s]$ fonéticamente normal de "asa", con los labios tensos y abiertos, a la $[s]$ entre dos vocales labializadas [o], con los labios abocinados y redondeados, hay bastante diferencia: la labialización provoca un descenso en el nivel de las frecuencias, una tendencia hacia un timbre más grave, debido al aumento de volumen de la cavidad de resonancia anterior.

2. ${ }^{-}$Vista la diferencia de frecuencias que existe para cada informante en los valores de [-s-] según su contorno vocálico, podemos deducir fácilmente que las diferencias en los valores de la [s] en [-st-] y en [-s-], para un informante y contorno, son verdaderamente despreciables, pucs ni pueden ser genéticamente diferentes, ni lo son genémicamente. Eisto

1 [s] fonéticamente normal. 
es, ni son, ni podemos percibir las realizaciones de $|s|$ en $[-s t-]$ y en $[-s-]$ como alófonos, diferentes.

3..$^{\circ}$ Los valores medios para la [s] de [-st-] son: $2896,5 \mathrm{~Hz}$ (informante figura 7); $3918,37 \mathrm{~Hz}$ (informante figura 8); 3614,62 Hz (informante figura 9).

Los valores medios para la [s] de [-s-] son: $2855,2 \mathrm{~Hz}$ (informante figura 7); $3948,75 \mathrm{~Hz}$ (informante figura 8); 3574, I2 $\mathrm{Hz}$ (informante figura 9).

De donde podemos concluir que las diferencias de los valores medios. de [s], en las situaciones antes expresadas, son prácticamente nulas.

4. Según se desprende del cuadro de duraciones la [s] del grupo [-st-] tiene una duración bastante menor que la de [-s-]: los valores medios de la duración de [-st-] son los siguientes: 7,1 c. s. (informantefigura 7); 10,2 c. s. (informante figura 8); I0,2 c. s. (informante figura 9). Los valores medios de la duración en [-s-] son: $I I, 4$ c. S. (informantefigura 7); 16,8 c. s. (informante figura 8); I4 c.s. (informante figura 9).

Esta duración menor en la [s] implosiva de [-st-] confirma, una vez. más, la tendencia del español hacia la desaparición de los sonidos implosivos, con la posterior constitución en silabas del tipo / cv/, abiertas ${ }^{1}$.

5. Pese a esta disminución de la duración, de la tensión articulatoria, y de la perceptibilidad que lleva consigo todo sonido implosivo ${ }^{2}$, la articulación de la [s] de [-st-] se mantiene alveolar y no dental.

En la figura ro reproducimos los espectrogramas de una frase en la: que se producen los contornos $\mid s+d, t /$ : "L,as damas están vestidas",. emitidas por los informantes de las figuras 7,8 y 9, respectivamente. Podemos observar claramente cómo las frecuencias de la fricación comienzan a la misma altura; es notorio señalar, por su proximidad, la. igualdad de las dos [s] de la parte "damas están". Aún hay pendientes. otros dos problemas: uno es el del grado de sonorización de $[s]$ ante la: dental sonora, y otro es el de la oclusión o fricación de $|d|$ precedido de $|s|$. En los espectrogramas I y 2 de la figura ro, $|d|$ se realiza como [d] tras [s], y ésta es sorda; por el contrario, en el espectrograma número 3 . de la nisma figura, $|s|$ se realiza como $[z]^{3}$, y $|d|$ como $[\vec{d}]$. De esta. cuestión trataremos en otra parte.

\footnotetext{
I V. BERTIL MLALAUERG. Estudios de fonética hispdnica. Madrid, $C P h$, I,. C. S. I. C., 1965, pp. 3-49.

- V. BoIIUSIAV HAI,A. La stlaba, su naturaleza, su origen y sus transformaciones. Madrid, CPh, III, 1966, pp. 28-33.

3 Debemos advertir que este alófomo, [z], es la realización de una consonante normalmente sorda que se lia realizado con cierto grado de sonoridad; es, por lo. tanto, sonorizada.
} 
Pensemos, además, que en las fonéticas descriptivas de otras lenguas no hay referencias a estos alófonos dentales: Daniel Jones, en su An Outline of English Phonetics (Cambridge, I957), no los señala, pese a las descripciones minuciosísimas de $[s, z]^{1}$, transcribiendo los ejemplos en los que se produce [s + dental], del siguiente modo: [ju:st] used to, [ju:zd] used, [zest] zest; para el fonetista inglés, la [s] es una "breathed blade-alveolar fricative consonant", siempre ${ }^{2}$.

Bohuslav Hála tampoco señala esta variante para el checo en su obra Uvedené do Fonetiky Cestiny, Praga, Ig62, para quien la [s] es predorsoalveolar ${ }^{3}$.

En alemán, la $[s]$ puede ser predorsoalveolar o predorsodental, según señalan Carl y Peter Martens en su Phonetik der Deutschen Sprache, München, I96r 4, pero no señalan, en los abundantes ejemplos citados en la obra, que, cuando la [s] predorsoalveolar se encuentra en contacto con $[t]$, se dentaliza ${ }^{5}$. Debemos señalar, sin embargo, que para HansHeinrich Wängler, en sus obras Atlas deutscher Sprachlaute, Berlín, I96I ${ }^{\circ}$ y Grundriss einer Phonetik des Deutschen, Maxburg, I960?, tanto la [s] como la $[z]$ son predorsodentoalveolares, sin que tampoco señale variantes sólo dentales. En realidad, compartimos mejor la opinión de Wängler al caracterizar las $[s, z]$ alemanas como dentoalveolares, por las razones que más abajo aducimos.

Maurice Grammont no señala en su Traité practique de prononciation française la [s], pese a los ejemplos que aduce del tipo ubuste", (poste), "astre", "style», etc. ${ }^{8}$. Tampoco aparece señalado este alófono en el Traité de prononciation française, de Pierre Fouché ${ }^{\circ}$. Ni asi mismo lo señalan para el italiano Robert A. Hall, Jr. en su Descriptive Italian Grammar ${ }^{10}$ ni Pierina Borrani Castiglione en su Italian Phonetics, Diction and Intonation ${ }^{11}$.

En catalán, sin embargo, nos encontramos de nuevo con la presencia de $[s, z]$, señaladas por Antonio M. Badia Margarit en sus obras

P. P. 185-r9o.

2 P. 185 .

3 Pp. 240-24I.

1 P. 167 .

- Pp. r67-r76. En las imágenes que muestran los autores en el cuadro i 8 se reproducen sólo las articulaciones ápicoalveolar y predorsoalveolar.

- Cuadro número 8.

7 Pp. 79-8x.

8 Pards, 195I, pp. 73-74.

- Paris, 1956, pp. 355-362.

10 New York, r948, pp. 9 y Ir.

"New York, 1957, pp. 18-19. 
Gramática catalana, Madrid, $1962^{1}$ y Gramática Histórica catalana, Barcelona, I95 ${ }^{2}$, quien, siguiendo probablemente el Manual de pronunciación, incluye estas dentalizaciones junto a las asimilaciones de la nasal y lateral. Aprovechando las investigaciones que sobre el dominio de la fonética catalana se están llevando a cabo en el Laboratorio de Fonética de Madrid, por Ramón Cerdá, me he permitido usar parte de sus materiales para comprobar estos extremos en nuestra lengua vecina.

En las figuras II, I2, I3 y I4 están representados los esquemas articulatorios de $[s, z]$ catalanas en los contornos [-st-, -zd-]: la figura II es la [s] de [féstu] de la frase "Fes-t'ho fer un dia de festa»; la figura i2 es la [s] de [fésta] de la misma frase; la figura I3 es la [z] en [trqzdal], de la frase "Ja n'he tret un tros del pot); y la figura I4 es la [z] de [äazdibuisa] de la frase "Des d'aquí ja es desdibuixa" ${ }^{3}$. Al igual que en las articulaciones castellanas que mostrábamos en las figuras $\mathrm{I}-6$, la constricción de esta [s] es plenamente alveolar, sin ningún asomo de dentalización. Compárese con la articulación fonéticamente normal de la [s] de [máss] en la frase "Zona de massa pobresan, de la figura I5.

En la figura 16 se encuentran los espectrogramas de otro informante catalán, en los que se dan las distinciones st/s, en los siguientes pares míuimos: llista/lliça, pasta/passa, rosta/rossa, pesta/peça. Como puede observarse claramente, la $[s]$ en $[-s t-]$ y $[-s-]$, en cada contorno, tiene la misma frecuencia de aparición.

Las investigaciones que se realizan sobre este dominio linguiístico abundarán en nuestra tesis de que $/ s+$ dental/ se realiza, al igual que en castellano, como $[s, z+$ dental $],-y$ no como $[s, z+$ dental $]$.

De todo lo expuesto anteriormente podemos afirmar que los alófonos dentales de $\mid s /$ en el sentido descrito por Navarro, y transcrito por nosotros más arriba no tienen existencia en castellano, ni, seguramente, en catalán 4. Aunque la lengua esté situada cerca de los incisivos, como ocu-

1 Pp. 8I-82.

2 P. 100.

- Estas frases pertenecen a un informante culto catalán, universitario, y cuya pronunciación es correcta. La velocidad de elocución es normal.

- Don RAMón MfENÉNDEz PIDAL, al hablar de la no monoptongación posterior a la diptongación de ě en los casos de [-st-] comenta: ‘P. Fouché, en la Revue Hispanique, IXXVII, 1929, pp. 34-36, supone una diferencia de silabeo entre vispera y siesta, que no ballo sostenible. La causa por que vispera monoptonga y siesta no, debe ser que en el grupo sp la $s$ tiene más carácter alveolar prepalatal, y en st más carácter dental (Manual de Gramática histórica española, p. 56, nota I). Nosotros encontramos insostenible la tesis de $P$. Fouché, pero no nos convence tampoco la idea de que el mantenimiento de la diptongación se deba al carácter 
rre en variadas articulaciones dialectales del castellano, si se percibe la [s] con todo el conjunto de características acústicas que antes hemos mencionado es que hay contacto alveolar, y este determinativo de lugar articulatorio debe constar al describir la articulación, ya que, si predominase la constricción dental, las características acústicas serían bien diferentes, percibiendo en este caso un sonido próximo a $[\theta]$.

\section{ANTonio Quiris.}

Departamento de Fonética del C. S. I. C. Madrid.

dental de la $s$. In primer lugar, la $s$ del grupo $s p$ no tiene carácter alveoloprepalatal, sino claramente alveolar, como comprobamos continuamente en nuestros radiofilmes. En segundo lugar, la diferencia entre la $[s]$ del grupo [-sp-] y la del grupo [-st-], en cuanto a asimilación de la oclusión sorda siguiente se refiere, consiste en que en el priner caso, $[-s p-]$, la $[s]$ no es seguida por ninguna articulación lingual, ya que $[p]$ es labial y no influye en ella, la lengua después de la emisión de [s] queda suelta, libre, mientras que en [-st-] la articulacion que sigue a la $[s]$ es otra lingual, y aunque la $[s]$ se inantiene alveolar siempre, se verá influida en su momento distensivo por la articulación de la linguodental siguiente, $[t]$. Resumiendo: la [s] en [-st-] no es dental; en el caso de la no monoptongación es posible que influya la articulación dental sigulente a [s], la consonante [ $l$ ]; pero creemos que será mejor buscar la explicación del fenómeno por otros carninos. 